\title{
EDITOR'S NOTE ON SPECIAL EDITION ON ORAL HEALTH
}

This special edition of Dental Anthropology is based on a symposium from the 2018 American Association of Physical Anthropologists annual meeting entitled, Reevaluating the Meaning of 'Oral Health' in Bioarchaeology that I co-chaired with James P. Fancher. The goal of this symposium was to begin a dialogue on how oral health is defined and evaluated in a bioarchaeological context. Invited participants explored definitions and interpretations of this term within their own work. Out of the initial discussion at this symposium, presentations were turned into the manuscripts presented here. The volume begins with an outline of various conditions that are traditionally used in studies of oral health. The articles that follow explore traditional markers of oral health, predominately focused on periodontal disease and dental caries. Interpretations are then nuanced within a biocultural context using the archaeological record and what is known abut the etiology and progression of these conditions.

The resulting volume is a thoughtful evaluation of how oral health can be studied in bioarchaeology. The hope is that discussions will continue and further questions will be raised about bioarchaeological research and its limitations. With particular attention to terminology, the limits of diagnoses, the integration of clinical literature, and the development of advanced methods of study.

Thanks to the many authors who contributed to this volume and those who contributed to the initial symposium. Their work, discussions, and contributions to this journal are appreciated and will serve to grow the study of pathological conditions of the oral cavity and contribute to a better understanding of oral heath in the past.

MARIN A. PILLOUD

Editor of Dental Anthropology

Department of Anthropology

University of Nevada, Reno

Reno, NV 89557 